\title{
ANÁLISE ACERCA DA INFORMAÇÃO, DO CONHECIMENTO E DO APRENDIZADO COMO ESTRATÉGIAS EM RESPOSTA AO AMBIENTE DE CONCORRÊNCIA SISTÊMICA
}

\author{
ANALYSIS REGARDING INFORMATION, KNOWLEDGE AND LEARNING AS
}

STRATEGIES IN RESPONSE TO SYSTEMIC COMPETITIVE ENVIRONMENT

Paulo César Elias
Jorge José Elias

Resumo: Sob a ótica da concorrência sistêmica acelerada pelo fator da globalização, aliadas as constantes variações dos mercados proporcionados pelas crises econômicas mundiais, cria-se um cenário altamente instável e competitivo em que diversas estratégias organizacionais acabam sendo insuficientes, levando por vezes muitas organizações a sucumbir. Neste contexto, observa-se que diversas empresas situadas nos países de industrialização recente, como as da Ásia, reacendem a questão da importância do uso do aprendizado, do conhecimento e da informação como alicerce para vencer as ondas de turbulência presentes no capitalismo. Baseado neste pano de fundo, este artigo propõe inicialmente uma discussão sobre o tema considerando suas relações com a informação, o conhecimento e o aprendizado, apoiando-se nas contribuições da Ciência da Informação e, seguidamente, investigando como as estratégias propostas por diferentes autores da área de Administração Empresarial abordam o tema.

Palavras-chave: Informação. Aprendizado. Conhecimento. Administração. Concorrência.

Abstract: From the viewpoint of competition systemic accelerated by a factor of globalization, coupled with the constantly changing market provided by the global economic crisis, it creates a highly unstable and competitive scenario in which several organizational strategies turn out to be insufficient, sometimes leading many companies to succumb. In this context, it is noted that several firms in the newly industrializing countries such as Asia, rekindle the question of the importance of using learning and knowledge as a foundation to overcome the waves of turbulence present in capitalism. Based on this background, this paper proposes an initial discussion of the terms information, knowledge and learning by relying on contributions from Information Science, and subsequently investigated by the research literature, the verification of the strategies proposed by various authors the area of Business Administration study the subject.

Keywords: Information. Learning. Knowledge. Management. Competition.

\footnotetext{
${ }^{1}$ Mestre em Ciência da Informação pela PUC-Campinas, professor dos cursos de Administração e de Sistemas de Informação da Faculdade Cenecista de Capivari e da Faculdade Santa Bárbara. E-mail: pcelias@gmail.com

${ }^{2}$ Graduado em Economia pela Universidade Metodista de Piracicaba e Mestre em Administração pela Faculdade Cenecista de Varginha. Professor titular da Faculdade Cenecista de Capivari - CNEC. E-mail: jorgejelias@gmail.com
}

Enviado em: 02/05/2012 - Aceito em: 13/12/2012. 


\section{INTRODUÇÃO}

Os reflexos da luz da incerteza provavelmente brilharão durante um longo tempo na economia global. De certo, talvez esse seja o ponto central do capitalismo que, durante décadas, se revela sempre em mutação, ou como descreveu Schumpeter (1982) há tempos por meio da "teoria das flutuações reversivas" - que prosperidade e infausticidade são condições naturais do capitalismo. Entretanto, conviver num cenário de turbulências exige não apenas que as organizações entendam o contexto, mas e, fundamentalmente, direcionem seus esforços para se adequar as mudanças e, possivelmente, seguir o viés da construção e exploração do "novo".

Contudo, não se pode deixar de lado que o designado de "novo" na sociedade contemporânea pode adquirir status de conhecido em poucos instantes. Isso em grande parte devido às novas tecnologias, que avançam muito rapidamente e são capazes, por exemplo, de promover significativas melhorias nos modos de produção em curtos espaços de tempo. Essa situação é comprovada em Kim (2005) pelos rápidos processos de imitação existentes em algumas economias de industrialização recente, e também corroborada por Peppers e Rogers (1994) que afirmam: “devemos admitir que a rapidez com que os imitadores alcançam os inovadores é maior do que nunca $[\ldots]$ ”. Há também que se destacar que as redes de informação atuais, que conectam pessoas de qualquer lugar, acelerando a circulação de informações, rompendo barreiras antes existentes, são utilizadas também, possivelmente não menos eficazmente, pelas empresas.

Dessa forma, faz-se necessário um realinhamento na discussão do viés anteriormente estabelecido, sendo que por diversas vezes as rápidas mudanças e as turbulências do mercado podem submeter muitas organizações a rumar ao "desconhecido". Verifica-se que este cenário é influenciado por diversos fatores, o qual submete à situação de concorrência sistêmica. Para Passos (1999, p.77-78) o que cria o viés de "competitividade sistêmica" é o fato ao qual a concorrência entre empresas são provocadas por fatores internos e externos, conforme cita o autor:

[...] macroeconômicos (taxa de juros, oferta de crédito, taxa de câmbio), os políticoinstitucionais (tributação, poder de compra do Estado, esquemas de apoio ao risco tecnológico), os regulatórios (políticas de proteção à propriedade intelectual, de proteção ao consumidor, de defesa da concorrência, a legislação ambiental), os infra-estruturais (disponibilidade, qualidade e custos dos transportes, das telecomunicações, da energia e de serviços tecnológicos), os sociais (a qualificação da mão-de-obra, as políticas de educação e formação de recursos humanos, a política trabalhista e de seguridade social, o grau de exigência dos consumidores), os 
internacionais (as tendências do comércio internacional, os fluxos internacionais de capital, de investimento de risco e de tecnologia, as relações com organismos multilaterais, acordos internacionais, políticas de comércio exterior), e ainda os aspectos relativos à distribuição espacial da produção. (PASSOS, 1999, p.7)

Contudo, observa-se com nitidez a existência de traços oriundos da globalização presentes nos diversos fatores da chamada concorrência sistêmica, fundamentalmente porque a globalização afeta, como afirma Chesnais (1996, p.115), todas as empresas. Sua manifestação é constatada também no grande volume de inovações dos processos produtivos provocados, principalmente, pelo desenvolvimento de novas tecnologias, Kim (2005), incluindo, neste caso, as mudanças provocadas pela rápida ascensão dos países de industrialização recente, os quais têm necessidade de adaptar seus processos de produção para entrar na disputa do mercado mundial. Outro fator consiste no mercado financeiro que, uma vez mundializado, oscila e afeta a todos rapidamente com quaisquer crises, como os casos da crise econômica de 2008/2009 e mais recentemente com a crise na Grécia. Essas variações do mercado em geral, provocadas em maior dimensão pelas crises financeiras e econômicas recentes podem afetar diretamente a produção industrial, pois, no momento que os investimentos internacionais se retraem, diminui paralelamente os fluxos de aporte na produção em resposta ao sinal vermelho. A título de exemplo, constata-se no Brasil uma retração da produção industrial de bens de capital e de bens de consumo duráveis na ordem de 22,6\% e 14,5\% em 2009. (BOLETIM..., p.100).

É sustentado na conjuntura da concorrência sistêmica que, as diversas estratégias empresariais existentes, podem, por muitas vezes, não suportar as transformações em curso, submetendo várias organizações a soçobrar. Mas, se por um lado a concorrência sistêmica traz perturbações que conduz ao resgate do "desconhecido", por outro pode revelar também a ideia de que o conhecimento e as experiências acumuladas são ferramentas fundamentais para enfrentar o contexto. Assim, o que em determinado momento está ligado com o "improvável” ou o "desconhecido", sob outra ótica, possa ser o velho "conhecido" de experiências acumuladas. Estabelecida a conjuntura, indagam-se como hipóteses a importância da informação e do conhecimento como instrumentos para as organizações e, se sua utilização como estratégia, pode levar as mesmas a obter vantagens necessárias para a sobrevivência no atual contexto. É firmado nesta hipótese que a presente pesquisa visa explorar as contribuições que a informação, o conhecimento e o aprendizado possam efetivamente 
oferecer para as organizações em tempos de concorrência sistêmica. Para tal será realizada uma análise bibliográfica dos estudos existentes sobre o assunto, primeiramente expondo os diferentes conceitos entre informação e conhecimento, alicerçado inicialmente na Ciência da Informação e, na sequência, na área de Administração de Empresas, analisando os diferentes estudos existentes sobre estratégias para as organizações sobreviverem no cenário altamente competitivo.

\section{SOBRE INFORMAÇÃO, APRENDIZAGEM E CONHECIMENTO}

Informação e conhecimento são exemplos de dois termos empregados na sociedade contemporânea com grande frequiência. Isso, em maior proporção, devido às novas tecnologias da informação que permitem, em certa medida, maior facilidade e velocidade no acesso às grandes redes de informação. No entanto, apesar de possuírem relações estreitas, apresentam aparentes diferenças entre os conceitos dos termos, os quais, na maioria das vezes, são empregados de maneira similar. Já o termo aprendizagem desponta por inúmeras vezes em diversos estudos relacionados com a administração contemporânea. Não será realizada nesta pesquisa uma profunda análise dos conceitos, mas sim uma breve exposição entre as diferenças e proximidades existentes entre eles.

Uma das idéias que definem o conceito de conhecimento é compartilhada por Le Coadic apud Robredo (2003, p.4), que esclarece:

\footnotetext{
Um conhecimento (um saber) é o resultado do ato de conhecer, ato pelo qual o espírito apreende um objeto. Conhecer é ser capaz de formar a idéia de alguma coisa; é ter presente no espírito. Isso pode ir da simples identificação (conhecimento comum) à compreensão exata e completa dos objetos (conhecimento científico). O saber designa um conjunto articulado e organizado de conhecimentos a partir do qual uma ciência - um sistema de relações formais e experimentais - poderá originar-se.
}

Este ponto de vista considera que o conhecimento deriva do ato de conhecer, e estabelece relação intrínseca com o processo de aprendizado, sendo que a informação serve como insumo desse processo. Já o conceito de informação pode estreitar sua relação com o conhecimento a partir do momento em que existe a necessidade de se ampliar o conhecimento do indivíduo, exemplificado em Le Coadic (1996, p.9): 


\begin{abstract}
Nosso estado (ou nossos estados) de conhecimento sobre determinado assunto, em determinado momento, é representado por uma estrutura de conceitos ligados por suas relações: nossa 'imagem do mundo'. Quando constatamos uma deficiência ou uma anomalia desse(s) estado(s) de conhecimento, encontramo-nos em um estado anômalo de conhecimento. Tentamos obter uma informação ou informações que corrigirão essa anomalia. Disso resultará um novo estado de conhecimento.
\end{abstract}

Baseado neste viés, a informação difere do conhecimento, estabelecendo-se como ferramenta fundamental no processo de construção do próprio conhecimento, sejam essas informações por meio digitais ou não. Aparentemente é a partir da atual configuração da sociedade que o conceito de informação entra, por diversas vezes, em contraste com outro conceito, como é o caso do dado. No entanto, o conceito de dado difere da informação. O conceito de dado remete à ideia de mensagens codificadas, passíveis de ser transmitidas por suportes físicos, seja por meio de fios, satélites, ou outros objetos. Para Oliveira (2005): “o dado é constituído por um código que pode disparar uma informação no receptor". Concluise, portanto, que o dado se transforma em informação quando o receptor consegue compreender seu significado.

Fundamentado em quatro aspectos (entidades, processos, intangíveis e tangíveis), Buckland (1991) apresenta como se organiza o fluxo da informação ${ }^{3}$, corroborando com a posição segundo a qual, para a informação ser processada pelos diferentes sistemas de informação e tecnologias, ela deve ser tangível, ou seja, relacionada com objeto ou dado. Dessa maneira, as diversas tecnologias existentes, presentes em diversos meios tecnológicos, servem apenas de suporte na comunicação de uma grande quantidade de dados. Transformar dados em informação e, por conseguinte, solidificá-los enquanto conhecimento são processos complexos, calcados no estado cognitivo de cada indivíduo, em seu modelo de mundo, na sociedade em que estão inseridos e nos valores por eles praticados.

Apresentados alguns conceitos, a discussão rema para uma lógica onde, aparentemente, facilita a compreensão em que o processo de aprendizagem organizado está relacionado com a necessidade da presença de fluxo de informações. Fluxo de informações

\footnotetext{
${ }^{3}$ Para Buckland (1991) a informação como conhecimento é intangível, não podendo ser tocada, relacionada com questões subjetivas e conceituais, comparada a crença e opinião. No entanto para a informação ser comunicada ela deva ser expressa, descrita ou representada por alguma forma física, como um sinal, texto ou comunicação. Dessa maneira, o processamento da informação está relacionado com os dois aspectos: O pessoal, para o sujeito obter informação, ou informar-se; e o processo materializado, mecanizado ou informatizado por computadores, neste caso sobre a forma de documentos, dados, "bits e bytes" como descreve o autor.
} 
necessariamente, como menciona Buckland (1991), podem distribuídos de diversas formas. Todavia, se considerarmos que a realização do fluxo de informação promove alterações no conhecimento, a presença deles não significa necessariamente que a geração de conhecimento esteja garantida. Compõe-se assim um sustentáculo para as discussões deste estudo, sendo que o entendimento dado para o fluxo de informação não é disciplinado apenas em sua circulação e em suas políticas de acesso, mas também na capacidade dos indivíduos participantes no processo de circulação em absorver as informações de modo que essas possam alterar seu estado de conhecimento.

Salutar transportar para essa discussão que o aprendizado não acontece somente em fluxos de informações organizados explicitamente. Ele pode estar contido, conforme Nonaka (2000), em experiências individuais tácitas, não se adequando portanto as técnicas tradicionais usadas por diversas empresas. Buscar aprendizagem em contextos de presença tácita de conhecimento pode exigir a utilização de técnicas distintas das existentes na prática de gerir a informação.

Outra discussão a respeito do conhecimento se encontra em Polanyi apud Lara (2004), a qual caminha para o rumo de que a criação do conhecimento passa por processos desenvolvidos em contextos sociais, isto é, construído de forma social. Nesta linha, é possível desenvolver a idéia da importância de se construir estratégias empresariais que busque a criação de grupos, intra e extra-organização, com o objetivo de desenvolver interações com foco para a socialização do conhecimento. Para Isidro-Filho e Guimarães (2010, p.130) o consenso sobre conhecimento dentro das organizações consiste que o mesmo está relacionado, segundo os autores, em:

[...] recurso ou ativo aprendido por meio de processos individuais ou coletivos de troca e análise de experiências vividas pela própria organização, bem como de experiências de outras organizações.

Constata-se, desta forma, que o processo de aprendizagem se faz presente também em cenários coletivos, envolvendo a colaboração, em que as trocas de informações tácitas e/ou explícitas podem, aparentemente, ser aproveitadas de forma mais eficientes na geração de conhecimento. Assim, pensar na hipótese que o aprendizado ocorre por meio de um processo no qual o fluxo de informações (tácitas e/ou explicitas), é a base (ou fonte) desse processo, pode ser um erro. Nonaka (2000) destaca que o conhecimento pode advir por métodos que não sejam apenas do ato de compartilhar informações, ou do emprego de

\begin{tabular}{l|l|l|l|l|l|l} 
(C) Rev. digit. bibliotecon. cienc. inf. & Campinas, SP & v.11 & n.1 & p.21-38 & jan./abr. 2013 & ISSN 1678-765X \\
\hline
\end{tabular}


tentativas e erros, mas também de palpites tácitos e intuições que os indivíduos podem ter diante de determinada situação. Porém, isso não tira a importância que se deva ter com o fluxo e com as políticas de informação dentro das organizações, pois, caso eles não sejam geridos de forma eficaz pode, evidentemente, comprometer diversos processos e setores de uma empresa. Davenport (1998) discute a informação dentro das organizações mostrando que as informações geridas de maneira estratégica, usando planejamento, podem efetivamente contribuir de diferentes formas para melhorar diversos processos organizacionais.

No contexto organizacional as discussões sobre do aprendizado e conhecimento reacendem quando estão envolvidos processos de mudanças ou de inovação. Em grande parte porque o cerne do capitalismo reside nestes processos. Entretanto, estudos de inovação não são assuntos recentes. Estão inseridos, institucionalizados e discutidos na economia e na sociedade por inúmeros autores, mais notadamente por Schumpeter (1984) descrito em seu processo de destruição criativa ${ }^{4}$, onde o mesmo afirma:

O impulso fundamental que inicia e mantém o movimento da máquina capitalista decorre dos novos bens de consumo, dos novos métodos de produção ou transporte, dos novos mercados, das novas formas de organização industrial que a empresa capitalista cria. (SCHUMPETER, 1984, p.112).

Se por um lado a inovação é força motriz do capitalismo, como Schumpeter já discutia a mais de 60 anos, os processos que envolvem sua sustentação por vezes aparentam ser esquecidos, ou abandonados, pelas empresas em momentos de turbulência. Isso fica evidenciado na medida em que para descrever a inovação como processo é também relevante, e necessário, reconhecer que ela acontece dentro de diversos ambientes, entre eles sociais e organizacionais, e, consequentemente, se torna indissociável das atividades de estudo e pesquisa. Essa situação corrobora com a ideia que informação, aprendizado e conhecimento são também essências do amplo sistema chamado organização.

Retoma-se, neste momento, o questionamento sobre a importância da presença do conhecimento, do aprendizado e da informação como pontos de essência nas estratégias empresarias em cenários de concorrência sistêmica.

${ }^{4}$ O processo de Destruição Criativa consiste na revolução de substituir o antigo, criando algo novo, proporcionando para o inovador o benefício de gozar da inovação durante algum tempo. O processo de Destruição Criativa de Schumpeter foi publicado pela primeira vez em 1942 na obra Capitalismo, Socialismo e Democracia.

\begin{tabular}{l|l|l|l|l|l|l} 
(C) Rev. digit. bibliotecon. cienc. inf. & Campinas, SP & v.11 & n.1 & p.21-38 & jan./abr. 2013 & ISSN 1678-765X \\
\hline
\end{tabular}




\section{AMBIENTE CONCORRENCIAL E ESTRATÉGIAS PARA SUPORTAR AS MUDANÇAS}

As informações que circundam o mundo dos negócios são de aceleração das mudanças, vencendo estratégias estabelecidas, tirando o fôlego dos gestores, submetendo-os a pensar em diversas estratégias, a exemplo do downsizing ${ }^{5}$. (CHAMPY, 1997, p.25). Diversos autores, entre eles Drucker (1996) e Champy (1997), relatam esse cenário e propõe diversas estratégias para as empresas enfrentar o contexto.

No entanto, uma das atividades mais afetadas pelo fator concorrencial é a dos processos produtivos. Quando se analisa o desenvolvimento econômico percebe-se claramente que o avanço tecnológico tem contribuído de forma significativa com o aumento da produtividade. Vale ressaltar que as melhorias nos modos de produção não é estratégia adotada recentemente pelas empresas para gerar lucro. Schumpeter (1982) descreveu por meio do fluxo circular, contido na "Teoria do Desenvolvimento Econômico", a importância fundamental que as melhorias e as inovações dos processos de produção podem efetivamente fazer com que as firmas obtenham mais lucros. Mesmo em países de economias de industrialização recente, como o caso da Coréia do Sul e Taiwan, (KIM e NELSON, 2005), a combinação do uso das novas tecnologias, apoiado no aumento significativo do aprendizado de novos processos produtivos, possibilitou a inserção desses países no competitivo cenário internacional.

Percebe-se que o acirrado ambiente concorrencial se amplifica principalmente após a institucionalização da globalização, aproximando as estratégias das empresas transnacionais para os chamados novos mercados $^{6}$. Dentre as diversas estratégias existentes, proporcionadas pela globalização, vale destacar as de exploração da mão-de-obra e também das inovações e melhorias de baixo custo dos processos produtivos existentes nas regiões dos países de industrialização recente. (KIM, 2005).

Fato importante, como constata Champy (1997), é que na maioria das vezes são os termos lucratividade e competitividade que submetem os gestores a pensar em mudança

\footnotetext{
5 Estratégia utilizada na administração para reestruturar a organização, reduzindo níveis hierárquicos e de negócios que não fazem parte das competências essenciais da empresa, com o objetivo de construir uma organização mais eficiente.

${ }^{6}$ Necessariamente, como afirma Drucker (1996, p.117), não são novos, existem em grande parte devido a real necessidade de países emergentes em melhorar a infra-estrutura física, mas notadamente nos sistemas de transportes e de energia.
} 
organizacional. Em termos práticos, é possível notar que os estudos de Champy (1997) estão intimamente ligados com a competitividade, ou seja, alguns gestores percebem o fator sistêmico da concorrência somente quando acontece a redução da lucratividade. Porém, Champy (1997), argumenta que quando uma organização tiver uma iniciativa de mudança organizacional esta deve centrar na eficácia organizacional, na busca de garantir melhorias em seus serviços, na qualidade, no crescimento e no retorno sobre o investimento. Para Champy (1997) a mudança traz consigo a necessidade que o autor chama de "reinvenção empresarial", o qual consiste necessariamente em mudar a estrutura organizacional, promovendo o gestor para o papel de ator principal como agente de mediação entre empresa, funcionários e demais indivíduos envolvidos no processo de mudança. Observa-se neste caso uma clara diferença entre a "reinvenção empresarial" descrita por Champy (1997), focada na eficácia, nas melhorias e na qualidade, com o que diversas empresas buscam em momentos de turbulência. É oportuno não esquecer que concentrar somente no gestor a responsabilidade central das mudanças não traduz o sucesso de casos recentes, como atestado em Nonaka (2000).

Outros autores, como Galbraith (1997), mencionam que a mudança ganhou status de "a ordem natural de tudo", e que as organizações devem ser planejadas em torno dela, criando estratégias que possibilite o que o autor denomina de organização "reestruturável". Galbraith (1997, p.107) argumenta que antigamente as organizações criavam uma vantagem competitiva e moldavam suas estruturas organizacionais baseadas nela, visando:

[...] funções, produtos e serviços, mercado ou região geográfica planejada para cumprir a fórmula de sucesso. Completando a integridade da organização, processos de planejamento e orçamento, sistemas de informações, processos de desenvolvimento de novos produtos, sistemas de remuneração, critérios de seleção e promoção, planos de carreira, avaliação de desempenho e séries de treinamento e desenvolvimento, estariam todos planejados e alinhados entre si e com a estratégia e a estrutura organizacionais. (GALBRAITH, 1997, p.107)

Mas com o passar do tempo vantagens competitivas são superadas, em grande parte por causa do avanço tecnológico, o qual faz com que a concorrência copie rapidamente as inovações e até mesmo as melhorem. Para Galbraith (1997), o alinhamento estratégico baseado em uma vantagem competitiva apenas pode trazer insucesso, mas, por outro lado, criar vantagens competitivas sem alinhamento tende a gerar conflitos entre atividades. Assim, Galbraith (1997, p.108), propõe que as empresas criem um "conjunto de vantagens temporárias e breves", devendo agir com flexibilidade e movimentos diversificados. O autor

\begin{tabular}{l|l|l|l|l|l|l} 
(C) Rev. digit. bibliotecon. cienc. inf. & Campinas, SP & v.11 & n.1 & p.21-38 & jan./abr. 2013 & ISSN 1678-765X \\
\hline
\end{tabular}


destaca ainda que o emprego de três recursos torna-se essencial para a organização "reestruturável": a interligação de unidades internas, ou seja, as equipes dos departamentos devem possuir interligação com os demais; sistemas contábeis de informações que determinem de maneira precisa os lucros e perdas; integração externa com parceiros buscando gerar novas vantagens competitivas. (GALBRAITH, 1997, p.108),

Ashkenas (1997) diz que as "curas mágicas", ou o processo de implementação de programas de mudança, entre eles qualidade total e reengenharia, não fortalecem a capacidade de muitas organizações em lidar com as transformações do mercado e complementa afirmando que muitos dos esforços desses programas transformam apenas em "rearrumação da organização existente". Para o autor, a organização do futuro está centrada em romper limites existentes entre "níveis e funções organizacionais", pois, são esses que bloqueiam e separam "pessoas, tarefas, processos e lugares." (ASHKENAS, 1997, p.123). Contudo, romper os limites não significa tirar as fronteiras, mas sim torná-las mais flexíveis. Ainda para Ashkenas (1997, p.123), as organizações deveram estão focadas em "transferir rapidamente idéias, informações, decisões, recursos, recompensas e providências para onde são mais necessários".

Em essência, pode-se notar que os diferentes autores propõem estratégias para lidar com a questão da mudança proporcionada pela competitividade. Mas, talvez a realidade repouse sobre a ideia na qual as empresas que se estruturam em torno de níveis gerenciais são, em sua maioria, apenas retransmissoras de informações. (DRUCKER, 1996, p.58). Essa mesma ideia submete ao entendimento que os problemas e as deficiências existentes em torno da comunicação intra e extra-empresa são comuns como os encontrados nos processos de retransmissão de informação ${ }^{7}$, cortando possivelmente, como afirma Drucker (1996, p.58), "pela metade" mensagens importantes.

Pensar em empresas com estruturas mais enxutas, com trabalhadores mais inteligentes e autônomos, remete ao resgate de um contexto histórico onde, conforme corrobora Passos (1999), o Japão já vivenciou vencer as dificuldades após a Segunda Guerra Mundial. Naquela época, os modelos de produção vigentes no ocidente, baseados nas técnicas fordistas de produção rígida e em larga escala, implementados, segundo Passos (1999) pelos

\footnotetext{
${ }^{7}$ É possível que Drucker (1996, p.58) refira aos problemas de transmissão de informação similarmente aos encontrados na teoria matemática da informação, mas especificamente os das falhas de transmissão causadas pelos ruídos ou interferências.
} 
“experts americanos", não eram compatíveis com um país cujos consumos e recursos eram escassos. Assim, novas técnicas de produção "enxuta", a exemplo do just-in-time, foram essenciais para ajustar os modelos de produção "às oscilantes condições e especificações de demanda, como foi o caso enfrentado por um grande número de empresas japonesas no pósguerra". (PASSOS, 1999, p.65). Outra questão importante abordada por Passos (1999) é que os trabalhadores das empresas japonesas agiam com um grau de autonomia operacional incompatíveis com os modelos tayloritas-fordistas ocidentais, o que exigia deles não somente conhecimento dos diversos postos produtivos, mas também e mais ampla, de todos os processos produtivos. Para Passos $(1999$, p.65) a principal diferença nas conhecidas técnicas japonesas é o fato de que os "aperfeiçoamentos contínuos nos procedimentos de trabalho foi delegada ao conjunto dos trabalhadores e a cada um como indivíduo".

Uma aparente semelhança com as estratégias adotadas pelas empresas japonesas no pós-guerra pode ser encontrada atualmente com os países de industrialização recente, os quais criaram estratégias mais enxutas de produção para vencer os desafios do atual ambiente concorrencial, a exemplo dos países asiáticos. (KIM, 2005). As empresas asiáticas, mas notadamente Coréia do Sul e Taiwan, acumularam competências por meio de processos graduais de aprendizado, necessária para se tornarem competitivas internacionalmente. Esse processo se deu em maior parte devido ao um aumento efetivo nos investimentos em pesquisa e desenvolvimento dentro dessas empresas. $\operatorname{Kim}(2005$, p.462) descreve que os investimentos empresariais em pesquisa e desenvolvimento na Coréia do Sul aumentaram significativamente nos últimos anos, assim como o registro de patentes que em curto intervalo de tempo chegaram a ser triplicados.

Outra estratégia interessante reside em Teece (2005), o qual propõe para os ambientes de forte concorrência um acompanhamento maior tanto do mercado como das tecnologias, focando a adoção das melhores práticas. Contudo, para Teece (2005, p.156) existem traços importantes na capacidade das empresas extraírem, da aprendizagem organizacional adquirida, conhecimento para uso na reconfiguração e na transformação da realidade. Teece (2005) corrobora com a idéia de que o aprendizado - relacionado num ambiente de colaboração - possa trazer alicerce sustentável para sobreviver no atual mercado concorrencial repleto de mudanças.

Dessa maneira, dentro do contexto de aprendizagem observa-se que as habilidades individuais estão proporcionalmente conectadas com seu emprego organizacional coletivo.

\begin{tabular}{l|l|l|l|l|l|l}
\hline (C) Rev. digit. bibliotecon. cienc. inf. & Campinas, SP & v.11 & n.1 & p.21-38 & jan./abr. 2013 & ISSN 1678-765X \\
\hline
\end{tabular}


Assim, o aprendizado requer códigos comuns de comunicação, ou seja, se realizem em um fluxo de informação conhecido dentro da organização, deixando de lado as antigas amarras existentes nos níveis gerenciais de diversas empresas. Ulrich (1997, p.213) descreve o exemplo da indústria de computadores, a qual se insere num cenário dinâmico e em constante transformação, como cita o autor "trata-se de um setor desordenado onde empresas cujos produtos bons e tornaram ocorrências isoladas e onde rápidas mudanças ofuscaram os produtos novos".

Para Ulrich (1997, p.213) uma das saídas para as organizações sobreviverem está em sua capacidade de aprender rápido, fazendo com que as idéias "codificadas" sejam compartilhadas pela organização, evitando possíveis erros já cometidos no passado. Ulrich (1997, 213) cita como exemplo:

\footnotetext{
A Coca-Cola está trabalhando para criar a capacidade de aprender rapidamente. Está colocando em cada região geográfica em cada linha de produtos profissionais talentosos cuja responsabilidade será sintetizar os segredos do sucesso e compartilhar essa informação com toda a empresa.
}

Fica claro o fato de que a concorrência sistêmica está levando as empresas a criar, e de certa forma a se acostumar, como uma cultura empresarial baseada em mudanças.

Sob este aspecto as empresas não têm mais alternativas diante da intensidade das revoluções tecnológicas e administrativa, senão a de segui-las, conforme corrobora Motta (2001). Segundo o autor, na sociedade contemporânea as relações sociais são compostas pela acessibilidade e subordinação das empresas às comunidades. É perceptível que o consumidor (as pessoas) tem interferido sob pelo menos dois aspectos: individualmente e como defensoras dos valores sociais. Após conferir que os modelos de produção que surgiram na Revolução Industrial tornavam os clientes dependentes da criação técnica da empresa o autor mostra a obsolescência deste modelo: “A tecnologia contemporânea e a organização virtual vieram repor essa prática secular, permitindo maior interferência do cliente no desenho de produtos e, portanto, no processo produtivo.” (MOTTA, 2001, p. 80).

Nesse sentido deixando o consumidor de ser um sujeito passivo em relação a empresa e passando a ter uma relação ativa, mostra a comunidade com maiores poderes sobre a empresa, mudando portanto as dimensões estratégicas das organizações onde passa-se a vigorar alianças e redes de colaboração mútua. Em uma extensa e importante pesquisa sobre estratégia e planejamento estratégico, Mintzberg, Ahlstrand e Lampel (2000) apresentam as

\begin{tabular}{l|l|l|l|l|l|l} 
(C) Rev. digit. bibliotecon. cienc. inf. & Campinas, SP & v.11 & n.1 & p.21-38 & jan./abr. 2013 & ISSN 1678-765X \\
\hline
\end{tabular}


premissas e críticas às 10 escolas do planejamento estratégico: Três escolas de natureza prescritiva (Design, Planejamento e Posicionamento; Seis escolas de natureza descritiva (Empreendedora, Cognitiva, Aprendizado, Poder, Cultural e Ambiental) e uma escola que seria uma combinação, configuração das outras (Escola da Configuração). Neste último modelo, o da escola da configuração, o foco é a estratégia como um processo de transformação, uma espécie de integração de todas as escolas, seguindo o estágio: turbulência - configuração - turbulência.

Assim, a estratégia empresarial precisa assumir a forma de um processo de aprendizado. Para a escola do aprendizado em geral é o sistema coletivo que aprende, sendo que as estratégias emergentes que surgem ao longo do processo devido as mutações constantes no ambiente interno (organização) e externo (economia, tecnologia, sociedade, político-legal, etc.) devem ser incorporadas às estratégias deliberadas, ou seja, planejadas inicialmente para serem executadas.

Contudo, vale destacar que a reinvenção, reestruturação, ou qualquer outra técnica que provoque alterações significativas na estrutura empresarial está estreitamente relacionada com rupturas de modelos já estabelecidos, causando provavelmente uma série de problemas inerentes a toda e qualquer mudança. É justamente neste ponto que aparenta existir o principal diferencial entre as empresas que se ajustam rapidamente a mudanças, e os conceitos da empresa flexível, baseada na aprendizagem e no conhecimento. Talvez seja neste mesmo ponto que repouse os erros cometidos quando o assunto é aprendizado e conhecimento, pois, a maioria dos gestores ocidentais, conforme corrobora Nonaka (2000, p.29), discutem a questão como sendo de ordem quantificável, ou seja, pensam na organização como "máquina de processamento de informação", esperando por resultados mensuráveis, como "maior eficiência, menores custos, melhor retorno sobre o investimento" (NONAKA, 2000, p.29).

Kanter (2010, p.12-19) relata que a IBM reconheceu sua capacidade de "integrar as partes, de combinar pessoas e de ser ágil” após a ajuda as vítimas do terremoto no estado de Gujarat na Índia em janeiro de 2001 e no tsunami de dezembro de 2004 nas ilhas indianas de Andamans e Nicobar. Conforme cita a autora:

[...] Nas ilhas Andamans, a IBM treinou estudantes do instituto politécnico de Port Blair em programas Linux e de código aberto e enviou os alunos para coletar dados de forma como os empregados da IBM fizeram após o terremoto de Gujarat. $\mathrm{O}$ envolvimento conjunto no trabalho formou e consolidou relacionamentos. [...] Mais tarde, a IBM ajudou o Indian Institute of Technology em Kharagpur, nas 
proximidades de Calcutá, a montar um centro de gestão de desastres e assistência. Todos estavam aprendendo. (KANTER, 2010, p.19).

Para Kanter (2010) um dos processos que determinam a condição de "vanguarda" para as empresas está relacionado com sua capacidade de estabelecer relações sociais sem o objetivo de ganhar dinheiro, mas sim de institucionalizar relações entre agentes sociais e terceiros, ganhando, intrinsecamente, uma forte rede de relacionamento e conhecimento baseado na colaboração que, segundo a autora, trazem no futuro os lucros. Ainda para Kanter (2010) empresas focadas em sólidos propósitos sociais e parceria com outras empresas, baseado num cenário de colaboração e aprendizagem, podem - em conjunto com outras propostas - trazer em longo prazo uma cultura mais duradoura fazendo com as empresas tenham reações mais rápidas a crises, facilitando o processo de adaptação a contínuas mudanças e renovações. Para a autora, algumas vantagens podem ser observadas frente a esse viés, sendo eles: maior amplitude do alcance de ideias, neste caso a inserção da empresa com a sociedade pode aproximar mais as ideias da empresa com a realidade num alcance mais amplo, ou seja, além das fronteiras da empresa, mais especificamente quando se aproxima os laboratórios de pesquisa e desenvolvedores dos usuários, reduzindo implicitamente o tempo de criação; soluções melhores e mais orientadas aos usuários, pois a inserção da empresa no social permite que as ideias sejam direcionadas para resolução dos problemas que vão além dos propósitos dos lucros; maior facilidade para gerar inovações, uma vez que as empresas podem recorrer a recursos exteriores à organização por meio do compartilhamento de ideias com seus parceiros; redução de conflitos e interesses políticos, já que o foco no bem da comunidade externa pode auxiliar na conquista do apoio da comunidade interna da empresa. (KANTER, 2010, p.115-117).

\section{CONSIDERAÇÕES FINAIS}

Ao analisar as diferentes estratégias descritas neste estudo percebe-se indícios da existência de um forte grau de relacionamento entre informação, conhecimento e aprendizado para com ambiente de turbulência enfrentado pelas empresas, sejam esses voltados para estratégias de produção de novos bens e serviços, incluindo as inovações, ou voltados para criar novos modelos de estruturas organizacionais capazes de se adaptar rapidamente as mudanças. Os desdobramentos entre essas relações são mais evidenciadas quando os

\begin{tabular}{l|l|l|l|l|l|l}
\hline (C) Rev. digit. bibliotecon. cienc. inf. & Campinas, SP & v.11 & n.1 & p.21-38 & jan./abr. 2013 & ISSN 1678-765X
\end{tabular}


conceitos são utilizados para destacar a importância de trazer a colaboração e a integração, intra e extra-empresa, para gerar inovações ou trazer soluções para os diversos problemas enfrentados no dia-a-dia das organizações. Nesse momento, fortalece-se a ideia que a geração do conhecimento ocorre em contextos sociais, mesmo notando que algumas ideias inovativas possam advir de indivíduos isoladamente.

Contudo, é salutar destacar que o tempo de maturação de uma empresa em engajar seu cerne para se adaptar ao novo ambiente, tratando estrategicamente as questões de informação, aprendizado e conhecimento, não pode ser pensado em curto prazo. Nas estratégias e nos estudos pesquisados evidencia-se que as empresas que se moldam rapidamente as mudanças, pautadas no aprendizado e no conhecimento, desenvolvem-nas há anos. Nesse cenário, fica claro que a inovação é parte do progresso e a empresa não pode desleixar desse ambiente tecnológico e de mutação que exige cada vez mais cooperação e apoio, para não trazer efeitos deletérios a ela mesma, as expectativas da comunidade, aos funcionários e ao emprego.

Importante destacar que gerir as informações, de forma que aconteçam num ambiente baseado na colaboração inter e extra-empresa pode proporcionar vantagens no futuro mas, por outro lado, pensar em fluxos de informações, aprendizado e conhecimento remete a condição de entender que as possíveis amarras existentes nas estruturas organizacionais necessitam ser superadas, quando não eliminadas. Isso não significa romper com a ordem, mas sim permitir que as pessoas envolvidas em processos que tragam maior eficácia e eficiência possam fazê-las sem ter que submetê-las aos longos e demorados processos de tomada de decisão existentes. Vale destacar que as tecnologias da informação existentes permitem o uso de ferramentas que proporcionem melhor eficiência na fluidez das informações. Contudo, o sucesso de aplicação dessas ferramentas está condicionado com a necessidade de estabelecer estratégias, políticas de uso e distribuição de informação que possam proporcionar de maneira eficaz o acesso e uso dos fluxos informacionais.

Nota-se também que o âmago dessas mudanças reside na chamada concorrência sistêmica, amplificada pelo mercado mundializado, e que dificilmente deixará de afetar, mesmo naquelas ainda não afetadas, todas as atividades da economia. Dessa forma, é possível estabelecer um alerta para alguns países emergentes, como o Brasil, destacando que a ações e políticas públicas de desenvolvimento não visem somente criação de políticas tecnológicas que, ao exemplo do passado recente na Ásia, firme parcerias de partilha de tecnologia com

\begin{tabular}{l|l|l|l|l|l|l}
\hline (c) Rev. digit. bibliotecon. cienc. inf. & Campinas, SP & v.11 & n.1 & p.21-38 & jan./abr. 2013 & ISSN 1678-765X \\
\hline
\end{tabular}


outros países. Pensar na inovação, como discutido, é primeiramente investir em alicerces sólidos de conhecimento tecnológico que permitam melhorias nos processos produtivos das empresas nacionais buscando o aumento da qualidade e redução dos custos de produção. Atenção e investimentos também devem ser dados para possíveis empreendedores, que a exemplo da Ásia, podem de forma efetiva contribuir com os processos de criação de novos produtos e processos produtivos.

\section{REFERÊNCIAS}

ASHKENAS, Ron. A roupa da nova organização. In: HESSELBEIN, Frances; GOLDSMITH, Marshall; BECKHARD, Richard (Org.). A organização do futuro: como preparar hoje as empresas de amanhã. São Paulo: Futura, 1997.

BOLETIM REGIONAL DO BANCO CENTRAL DO BRASIL. Impacto da crise econômica mundial sobre a indústria regional. v.4, n.1, jan.2010. Disponível em <http://www.bcb.gov.br/pec/boletimregional/port/2010/01/br201001P.pdf >. Acesso em 20 ago. 2010.

BUCKLAND, Michael. Information as thing. Journal of the American Society for Information Science, v.45, n.5, p.351-360, 1991.

CHAMPY, James A. Preparando-se para a mudança organizacional. In: HESSELBEIN, Frances; GOLDSMITH, Marshall; BECKHARD, Richard (Org.). A organização do futuro: como preparar hoje as empresas de amanhã. São Paulo: Futura, 1997.

CHESNAIS, F. A mundialização do capital. São Paulo: Xamã, 1996.

DAVENPORT, T. H. Ecologia da informação: por que só a tecnologia não basta para o sucesso na era da informação. São Paulo : Futura, 1998.

DRUCKER, Peter F. Administrando em tempos de grandes mudanças. 3 ed. São Paulo: Pioneira, 1996.

GALBRAITH, Jay R. A organização "reestruturável”. In: HESSELBEIN, Frances; GOLDSMITH, Marshall; BECKHARD, Richard (Org.). A organização do futuro: como preparar hoje as empresas de amanhã. São Paulo: Futura, 1997.

ISIDRO-FILHO, A., GUIMARÃES, T. Conhecimento, aprendizagem e inovação em organizações: uma proposta de articulação conceitual. Revista de Administração e Inovação, v.7, n.2. ago. 2010. Disponível em: http://revistarai.org/ojs2.2.4/index.php/rai/article/view/502. Acesso em: 25 ago. 2010. 
KANTER, R. M. Empresas fora de série: gestão da mudança para criar valor inovação e crescimento. Rio de Janeiro: Elsevier, 2010.

KIM, Linsu. O sistema nacional de inovação sul-coreano. In: KIM, L.; NELSON, R.R. (Org.). Tecnologia, aprendizado e inovação: as experiências das economias de industrialização recente. Campinas: Editora da Unicamp, 2005.

KIM, Linsu; NELSON, R.R. (Org.). Tecnologia, aprendizado e inovação: as experiências das economias de industrialização recente. Campinas: Editora da Unicamp, 2005.

LARA, C. R. D. A atual gestão do conhecimento: a importância de avaliar e identificar o capital intelectual dentro das organizações. São Paulo: Nobel, 2004.

LE COADIC, Y. F. A ciência da informação. Brasília. Briquet de Lemos, 1996.

MOTTA, Paulo Roberto. Transformação organizacional: a teoria e a prática de inovar. Rio de Janeiro: Qualitymark, 2001.

MINTIZBERG, Henry; AHLSTRAND, Bruce; LAMPEL, Joseph. Safári de estratégia: um roteiro pela selva do planejamento estratégico. Porto Alegre: Bookman, 2000.

NONAKA, Ikujiro. A empresa criadora de conhecimento. In: Gestão do conhecimento. Rio de Janeiro: Elsevier, 2000.

OLIVEIRA, V.P. Uma informação tácita. Revista Datagramazero, v.6 n.3, jun.2005.

Disponível em <http://www.dgz.org.br/jun05/Art_04.htm>. Acesso em 10 out. 2005.

PASSOS, Carlos A. K. Novos modelos de gestão e as informações. In: LASTRES, H. M. M; ALBAGLI, S. (Org.). Informação e globalização na era do conhecimento. Rio de Janeiro: Campus, 1999.

PEPPERS, D.; ROGERS, M. Marketing um a um: individualizado na era do cliente. Rio de Janeiro: Campus, 1994.

ROBREDO, Jaime. Da ciência da informação revisitada aos sistemas humanos de informação. Brasília: Thesaurus, 2003.

SCHUMPETER, Joseph A. Capitalismo, socialismo e democracia. Rio de Janeiro: Zahar Editores, 1984.

SCHUMPETER, Joseph A. Teoria do desenvolvimento econômico: uma investigação sobre lucros, capital, crédito, juro e ciclo econômico. São Paulo: Abril Cultural, 1982.

TEECE, David J. As aptidões das empresas e o desenvolvimento econômico: implicações para as economias de industrialização recente. In: KIM, L.; NELSON, R.R. (Org.).

Tecnologia, aprendizado e inovação: as experiências das economias de industrialização recente. Campinas: Editora da Unicamp, 2005. 
ULRICH, Dave. Organizando de acordo com a capacidade. In: HESSELBEIN, Frances; GOLDSMITH, Marshall; BECKHARD, Richard (Org.). A organização do futuro: Como preparar hoje as empresas de amanhã. São Paulo: Futura, 1997.

Como citar este artigo:

ELIAS, Paulo César; ELIAS, Jorge José. Análise acerca da informação, do conhecimento e do aprendizado como estratégias em resposta ao ambiente de concorrência sistêmica.Rev. digit. bibliotecon. cienc. inf., Campinas, SP, v.11, n.1, p.21-38, jan./abr. 2013. ISSN 1678-765X. Disponível em: $<$ http://www.sbu.unicamp.br/seer/ojs/índex.php>. 